\title{
Knowledge and Attitude of Preschool Children Parents Towards Professional Topical Fluoride Therapy
}

\author{
Shirin Taravati ${ }^{1, *}$ and Negin Lak ${ }^{2}$ \\ ${ }^{1}$ Department of Pediatric Dentistry, School of Dentistry, Ahvaz Jundishapur University of Medical Sciences, \\ Ahvaz, Iran \\ ${ }^{2}$ School of Dentistry, Ahvaz Jundishapur University of Medical Sciences, Ahvaz, Iran
}

\begin{abstract}
Purpose: Since various factors such as parents' attitudes and knowledge can affect the use of fluoride, this study aims to assess the relationship between children's parents' attitudes and knowledge towards preventive caries methods with their children's caries experience.

Materials and Methods: In this cross-sectional study, 110 parents of preschool children in Ahvaz were randomly selected. Using a questionnaire, parents' knowledge and attitude about fluoride therapy were evaluated, and their children's teeth were examined for dmft. Data were analyzed by Mann-Whitney and Kruskal-Wallis tests.

Results: The mean of parents' knowledge about caries prevention methods was $2.22 \pm 3.23$ of 9 , and the knowledge of $68 \%$ was poor, $21 \%$ moderate, and $11 \%$ was good. The mean of parents' attitude about caries prevention techniques was $9.5 \pm 2.05$ of 14 , and the attitude of $0 \%$ was poor, $60 \%$ moderate, and $40 \%$ was good. There was no significant relationship between parents' knowledge with gender, age, education, source of information, and dmft. There was a direct relationship between knowledge and the experience of professional topical fluoride (PTF). There was no significant relationship between the attitudes of parents with gender, the history of PTF, and the source of information. There was a direct, significant relationship between parents' attitude and their educational level, age, and child's dmft. Children's experience of PTF was $18.6 \%$.
\end{abstract}

Conclusion: Parents' knowledge and attitude towards fluoride roles in the prevention of dental caries were low. So, assigning programs to increase parents' knowledge and, subsequently, using caries prevention techniques is suggested.

Keywords: Knowledge, Attitude, Parents, Prevention, Caries.

\section{INTRODUCTION}

Different ways have been used for caries prevention over recent decades, but dental caries still is one of the most common diseases between children [1]. The incidence of decayed, missing, filled teeth (dmft/DMFT) was 5.84 for primary teeth (dmft) in 6 years old and 1.84 for permanent teeth (DMFT) in 12 years old Iranian children [2]. So, dental caries indices in Iranian children were classified as a severe range for primary teeth. Dental caries causes pain and discomfort, loss of school days, inability to learning, need for medical care, and affect children's quality of life [3]. Therefore we sought causes of this problem to establish preventive methods and programs to manage this problem.

Preventive methods applied in different ways, such as oral hygiene and dietary instructions, topical and systemic fluoride, and fissure sealants can significantly reduce dental caries $[3,4]$. Water fluoridation is one of the most effective ways of caries prevention, but water fluoridation does not use in IRAN, and the groundwater amount of fluoride in different areas of this country is

*Address correspondence to this author at the Department of Pediatric Dentistry, School of Dentistry, Ahvaz Jundishapur University of Medical Sciences, Ahvaz, Iran; Tel: 00986133205168; Fax: 00986133205320;

E-mail: shirin.taravati@gmail.com changeable [5,6]. Based on Jaafari-Ashkavandi's study, in Ahvaz city, the amount of water fluoride is low and widespread use of water purifiers lowers it near zero [7]. So pediatric dentists should employ topical fluoride (TF) methods in order to prevent dental caries. Decision making about professional topical fluoride (PTF) application in dental offices is complicated, and it depends on both dentists and parents [8-10]. Dentists are well aware of the benefits of PTF, but convincing parents to accept and consist of fluoride usage, needs their agreement. Parent's characteristics, knowledge, and experience can affect their performance about paying attention and spending money to use preventive methods [8-10].

Since that reduction of sugar intake and establishing good oral hygiene can not be achieved in most children, to manage this problem, PTF application is an effective way that reduces caries about 30-40\% $[11,12]$. However, in studies, parents' knowledge about preventive methods is low, and most of them are not aware of fluoride roles in caries [13,14]. So, enhancing parents' knowledge and attitude about these methods seems advantageous. Besides parental knowledge, one more obstacle in fluoride application is concerns about its toxicity and fluoride toxicity issues may drived parents unwilling to use it $[13,14]$. Studies have shown 
that many parents are not well prepared to bring their children to PTF and pursue it for more effectiveness $[15,16]$. We emphasized that caries experience and history of dental treatment could influence parents' experience about fluoride application, So in addition to demographic information, dmft of children in this study were determined. This study aimed to assess the knowledge and attitude of parents about the use of fluoride and its relationship with caries experience in Ahvaz city in the year 2019.

\section{MATERIALS AND METHODS}

\section{Study Population}

This cross-sectional analytical study was conducted on 110 parents of preschool children in Ahvaz city. This study was performed in two months from October to December 2019, on children between 2-5 years old who referred to a pediatric outpatient clinic for illness or routine checkups. We also included parents and children who came to an English language educational center for preschool children. The parents and children participated in the study based on inclusion and exclusion criteria.

Inclusion criteria included:

- Parents of children between 2-5 years old

- Inhabit in Ahvaz city in the past two years

- Healthy children without systemic disease, mental or functional disability

- Children without longtime usage of the medicine

- Exclusion criteria included: missing to complete all questionnaire questions.

- Uncooperative child for oral examination

- Existence of any systemic disease

- Mental or functional disability in the child

Before offering the questionnaire, the aims of the study were explained for parents and if they were willing participated in the study.

\section{Study Procedure}

A total of 110 questionnaires were completed. We employed a questionnaire consisting of 29 questions about demographic data, parental knowledge, and attitude preferences in the prevention of their children's dental caries by PTF application. This questionnaire was chosen from Tahani's study, modified based on our study goals [13]. This questionnaire contains three parts, and the first part was evaluated demographic information includes: gender, age, number of children, history of PTF and etc. In the second part of the questionnaire, questions related to the parental knowledge about caries prevention methods were asked with questions such as the role and efficacy of fluoride, PTF application steps, and PTF application intervals. In this section, there were 9 multiple-choice questions with the answers "yes", "no", "I don't know", and the scores of one or zero were considered for correct and incorrect answers. For assessing parent's knowledge, the score of which questions added and scores $0-3$ considered weak, 3-6 moderate, and 6-9 as good knowledge.

The third part of the questionnaire consisted of questions about parents' attitude towards PTF. Seven questions were asked with contents such as the cost and effectiveness of fluoride and its toxicity and side effects. In this section, the criterion for comparing the answers was three-part Likert questions with the options "Agree", "No idea" and "Disagree", score 2 was considered for the correct answers, score zero for incorrect answers and score 1 for the "No idea" responses. In evaluating the parents' attitude scores, the minimum score was zero, and the maximum score was 14 . Scores between 0 and 4 poor, scores between 5 and 9 moderate, and scores between 10 and 14 assigned good attitudes.

Then an examination of children's teeth was performed to examine the relationship between parents' knowledge, attitude, and their children's dental caries. The examinations were performed according to the WHO (World Health Organization) criteria [17]. The examination was performed by a single examiner, trained intern dentistry student wearing disposable gloves, and using mirrors. The light needed for the examination was illuminated by the flashlight of a cell phone. The examiner was calibrated by measuring the same children $(\mathrm{N}=15) \mathrm{dmft}$ between two weeks in a pediatric dentistry department, and intra-examiner kappa values were greater than 0.8 .

Younger children were examined in the knee-toknee position with the aid of their parents. The teeth were not dried before the examination, but food debris was cleaned with sterile dental gauze if necessary. Dental examinations were performed regularly from 
one tooth to the adjacent tooth. The dental caries examination included all surfaces. White spots, groove discoloration, and cavity-free lesions were not calculated as decayed teeth according to WHO guidelines, and only frank dental caries and cavities were calculated. To achieve a dmft score for a child, three items were examined, including the number of teeth with decayed lesions, the number of teeth extracted due to caries, and the number of filled teeth. Then these three numbers were added to get the $\mathrm{dmft}$ score of each child. $\mathrm{dmft}$ numbers were considered at three levels: 0-1 (low), 2-4 (moderate), and more than 5 (high) [18].

In the end, the parents were informed about their child's dental problems and were given instructions about oral hygiene, healthy nutritional habits, and prevention of oral diseases.

\section{Ethical Consideration}

One parent for each family participated. The aims of the study were explained for them and if they were willing, participated in the study. For each participant, informed consent was obtained, and they were assured that their information would be confidential. There were no mandatory participants, and no fees were imposed on them. This research was approved by Ahvaz Jundishapur University of Medical Sciences ethics committee, according to the Helsinki Declaration of 1975, as revised in 2000 (Ethical code: IRAJUMS.REC.1398.674).

\section{Data Analysis}

Descriptive statistics were utilized to consider frequency distribution and mean of variables. The nonparametric Mann-Whitney and Kruskal-Wallis tests were used to assess the correlation between demographic data and parents' knowledge and attitude. Dental caries were categorized as with or without caries, and the Kruskal-Wallis test was used to evaluate the relationship between parents' knowledge, attitude, and child's caries experience. Data analysis was calculated by SPSS software version 20 (SPSS Inc., Armonk, N.Y., USA), and the significance level was set as $p<0.05$.

\section{RESULTS}

One hundred and ten parents and their preschool children participated in the study. Parents were 25

Table 1: Distribution of Study Subjects According to Demographic Information

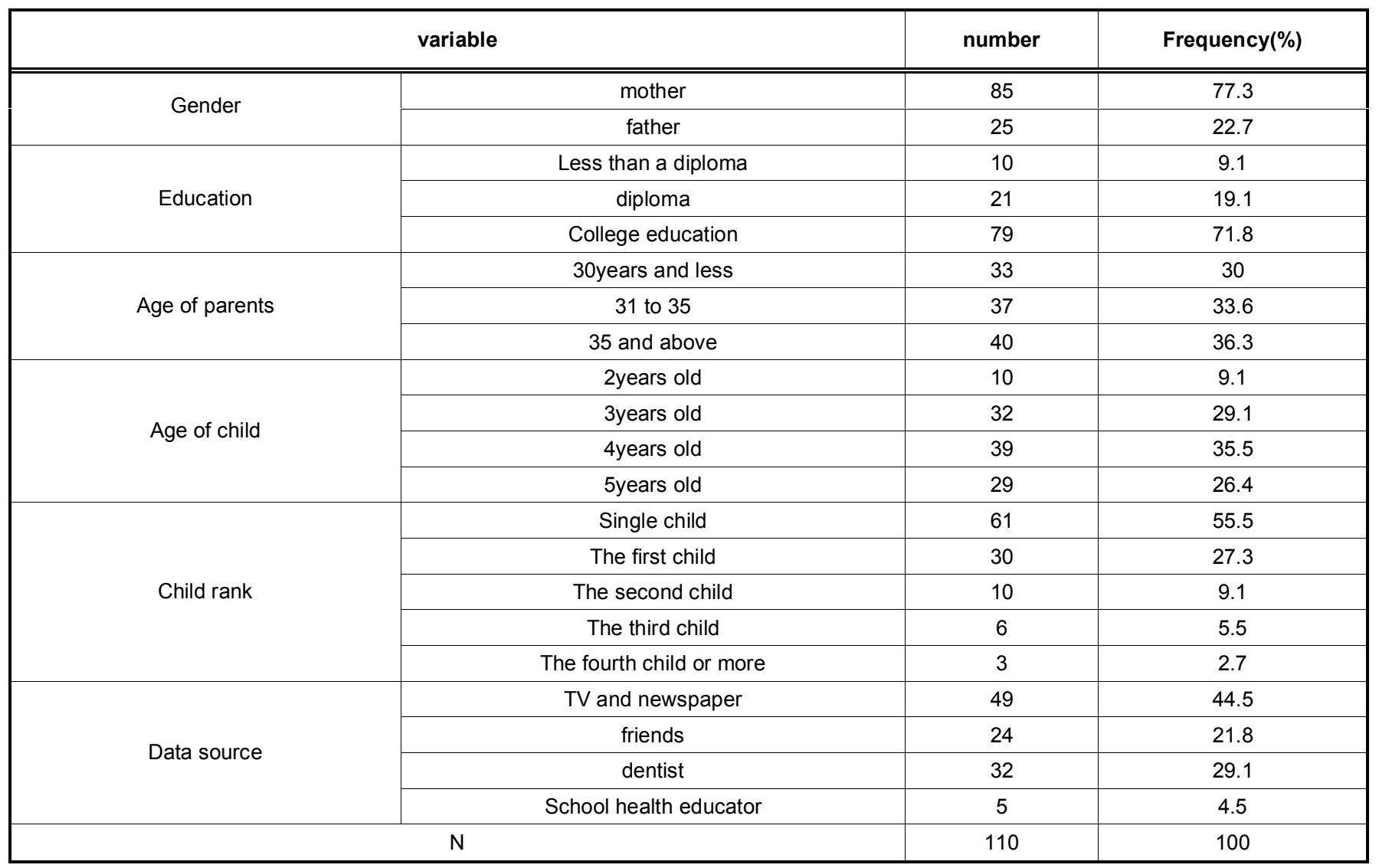


males $(22.7 \%)$ and 85 females $(77.3 \%)$. The mean age of parents was 33.5 years. Most of the parents were female, more than 35 years, had academic education, and had single children. The mean child's age was 3.7 years old (Table 1).

About PTF, most of the children had no history of PTF, and among whom had a history of PTF, most of them mentioned that they performed it in a private office and in less than 6 months ago. Moreover, in the parent's opinion, PTF cost was appropriate. The most mentioned parent's source of information was social media. The summary of the participant's responses to questions about their PTF experiences shows in Table 2.

\section{Knowledge of Parents about Caries Preventive Effect of PTF}

The mean knowledge score of parents was 2.22 \pm 3.23 (range $0-9)$, and $68 \%(n=75)$ of parents had poor knowledge about PTF. Mean knowledge values were more between mothers than fathers, but the difference was not significant. There was no significant relationship between knowledge and parents'

Table 2: Distribution of Parents and Children Experience of Dental Services

\begin{tabular}{|c|c|c|c|}
\hline \multirow{4}{*}{ Last dental visit } & 1 to 6 month ago & $\begin{array}{c}\text { number } \\
34\end{array}$ & $\begin{array}{c}\text { Frequency(\%) } \\
30.9\end{array}$ \\
\hline & 1 to 2 years ago & 20 & 18.2 \\
\hline & 2 to 5 years ago & 2 & 1.8 \\
\hline & Don't remember & 11 & 10 \\
\hline \multirow{5}{*}{ last dental service } & Teeth extraction & 8 & 7.3 \\
\hline & Filling teeth & 11 & 10 \\
\hline & fluoride & 12 & 10.9 \\
\hline & Just examination & 37 & 33.6 \\
\hline & Etc & 0 & 0 \\
\hline \multirow{3}{*}{ Experience of PTF } & Has a history & 18 & 16.4 \\
\hline & Has not a history & 86 & 78.2 \\
\hline & I don't know & 6 & 5.5 \\
\hline \multirow{3}{*}{ Treatment site } & Private office & 16 & 14.5 \\
\hline & Private clinic & 4 & 3.6 \\
\hline & School of dentistry & 3 & 2.7 \\
\hline \multirow{4}{*}{ cost of PTF treatment } & Dose not remember & 3 & 2.7 \\
\hline & It was expensive & 1 & 0.9 \\
\hline & It was appropriate & 16 & 14.5 \\
\hline & No idea & 5 & 4.5 \\
\hline \multicolumn{2}{|c|}{$\mathrm{N}$} & 110 & 100 \\
\hline
\end{tabular}


Table 3: Mean Parents Knowledge and Attitude According to Non-Parametrical Tests

\begin{tabular}{|c|c|c|c|c|c|}
\hline \multicolumn{2}{|c|}{ variable } & \multirow{2}{*}{$\begin{array}{c}\begin{array}{c}\text { Mean of total } \\
\text { Knowledge } \\
\text { M } \pm S D\end{array} \\
1.88 \pm 2.52\end{array}$} & \multirow{3}{*}{$\begin{array}{c}\text { p-value } \\
(P>0.05)\end{array}$} & \multirow{3}{*}{$\begin{array}{c}\begin{array}{c}\text { Mean of total } \\
\text { Attitude } \\
\text { M } \pm \text { SD }\end{array} \\
9.16 \pm 1.82 \\
9.6 \pm 2.12\end{array}$} & \multirow{3}{*}{$\begin{array}{r}\text { p-value } \\
(P>0.05)\end{array}$} \\
\hline \multirow{2}{*}{ Gender } & father & & & & \\
\hline & mother & $2.45 \pm 2.12$ & & & \\
\hline \multirow{3}{*}{ Age group } & $30 y e a r s$ and less & $2.3 \pm 2.13$ & \multirow{3}{*}{$(P>0.05)$} & $8.82 \pm 1.84$ & \multirow{3}{*}{$(P \leq 0.05)$} \\
\hline & 31 to 35 & $2.22 \pm 2.19$ & & $9.62 \pm 1.89$ & \\
\hline & 35 and above & $2.43 \pm 2.36$ & & $9.5 \pm 2.25$ & \\
\hline \multirow[t]{2}{*}{ Educational level } & $\begin{array}{l}\text { Has a university } \\
\text { education }\end{array}$ & $2.56 \pm 2.27$ & \multirow[t]{2}{*}{$(P>0.05)$} & $9.76 \pm 2.11$ & \multirow[t]{2}{*}{$(P \leq 0.05)$} \\
\hline & No university education & $1.71 \pm 1.99$ & & $8.84 \pm 1.77$ & \\
\hline \multirow{4}{*}{ Reason for visit dentist } & toothache & $2.42 \pm 2.06$ & \multirow{4}{*}{$(P>0.05)$} & $9 \pm 2.31$ & \multirow{4}{*}{$(P>0.05)$} \\
\hline & Filling teeth & $2.09 \pm 2.43$ & & $9.82 \pm 2.27$ & \\
\hline & Periodic examination & $2.92 \pm 2.43$ & & $9.82 \pm 2.15$ & \\
\hline & abscess & $3.5 \pm 4.95$ & & $12 \pm 0$ & \\
\hline \multirow{3}{*}{ History of fluoride treatment } & Has a history & $4.11 \pm 2.37$ & \multirow{3}{*}{$(P \leq 0.05)$} & $10.11 \pm 2.35$ & \multirow{3}{*}{$(P>0.05)$} \\
\hline & Has not a history & $2 \pm 2.05$ & & $9.44 \pm 1.99$ & \\
\hline & I don't know & $1.5 \pm 2.64$ & & $8.5 \pm 1.76$ & \\
\hline \multirow{4}{*}{ Data source } & TV and newspaper & $2.24 \pm 2.25$ & \multirow{4}{*}{$(P>0.05)$} & $9.46 \pm 1.95$ & \multirow{4}{*}{$(P>0.05)$} \\
\hline & Friends & $1.75 \pm 1.98$ & & & \\
\hline & School & $2.67 \pm 2.08$ & & $9.04 \pm 2.05$ & \\
\hline & dentist & $2.82 \pm 2.31$ & & $9.94 \pm 2.18$ & \\
\hline \multicolumn{2}{|c|}{ Mean } & $2.32 \pm 2.22$ & & $9.5 \pm 2.05$ & \\
\hline
\end{tabular}

educational level, age, cause of referral to a dentist, and source of information $(p>0.05)$. But, there was a significant relationship between knowledge and history of PTF, So parents with a history of PTF had higher knowledge about that $(p<0.05)$ (Table 3). Between seven questions about parents' knowledge, their score in the first question about fluoride effect on teeth was more than other questions. Parents' knowledge in questions about PTF treatment procedure, including forbidden time for eating or drinking, times of PTF in the year, and appropriate age for PTF was lower than other questions (Figure 1).

\section{The Attitude of Parents about the Caries Preventive Effect of PTF}

None of the parents had a poor attitude towards PTF. The mean parents' attitude was $9.5 \pm 2.05$ (range $0-14)$, and $66 \%(\mathrm{~N}=66)$ of parents had moderate

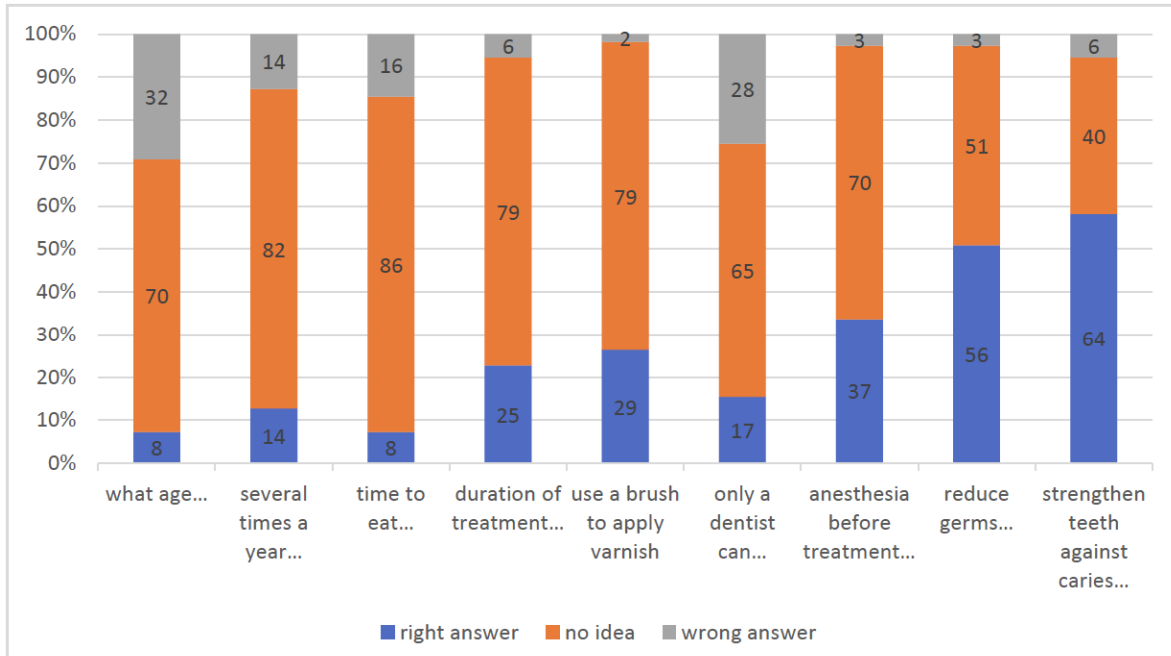

Figure 1: Parents' knowledge towards professional topical fluoride application. 


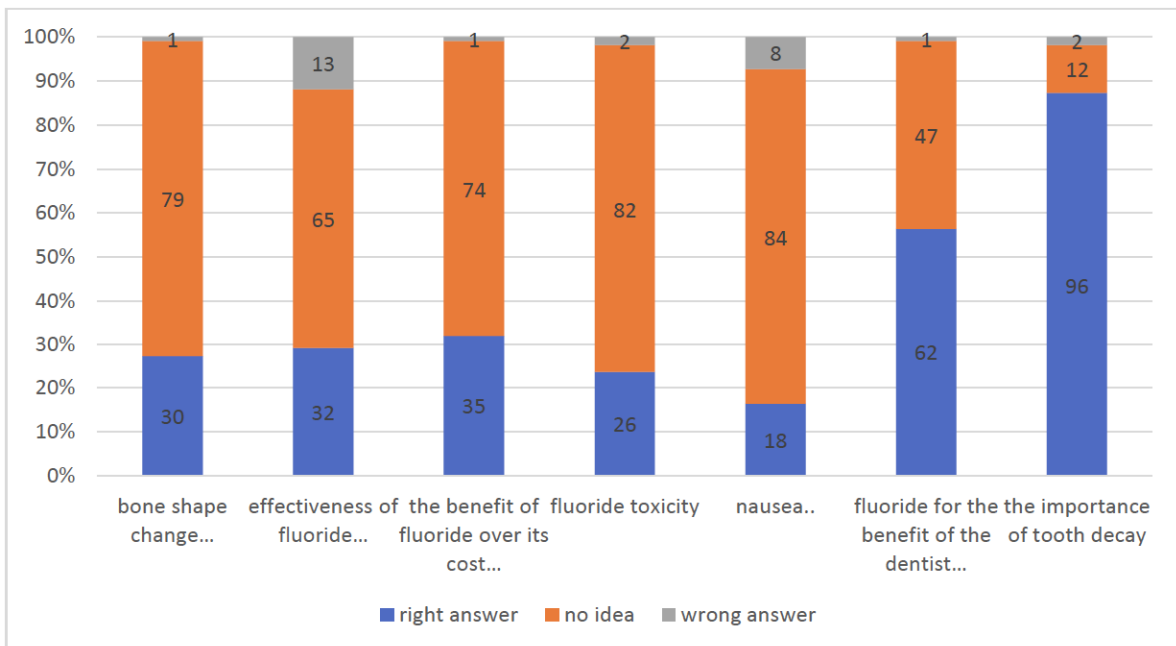

Figure 2: Parents' attitude towards professional topical fluoride application.

Table 4: Mean Knowledge and Attitude of Parents and Caries Experience of their Children

\begin{tabular}{|c|c|c|c|c|c|c|}
\hline \multicolumn{2}{|c|}{ variable } & number & $\begin{array}{c}\text { Knowledge } \\
\text { Mean } \pm S D\end{array}$ & $p$-value & $\begin{array}{c}\text { Attitude } \\
\text { Mean } \pm S D\end{array}$ & $p$-value \\
\hline \multirow{3}{*}{$\begin{array}{l}\text { Caries } \\
\text { (dmft) }\end{array}$} & dmft 0-1 & 47 & $2.22 \pm 2.23$ & \multirow{3}{*}{$P>0.05$} & $9.13 \pm 2.24$ & \multirow{3}{*}{$P<0.05$} \\
\hline & $\begin{array}{c}\text { dmft more } \\
\text { than } 1\end{array}$ & 63 & $2.4 \pm 2.23$ & & $9.78 \pm 1.87$ & \\
\hline & Total & 110 & $2.32 \pm 2.22$ & & $9.5 \pm 2.05$ & \\
\hline
\end{tabular}

attitudes. There was a significant relationship between parents' age and educational level and their attitude $(p>0.05)$. But gender, history of PTF, cause of dentists referral and source of information didn't have a significant correlation with parents' attitudes (Table 3 ).

Figure 2 shows parents' attitude for each question, the correct answers were about the preventive effect of PTF, and the lowest scores were assigned to questions about nausea after PTF and its complications.

\section{Knowledge and Attitude of Parents and dmft}

The mean dmft of children was 1.69. Mean dmft score of $68.2 \%(\mathrm{~N}=75)$ of children was low, $19.1 \%$ $(\mathrm{N}=21)$ were moderate, and $12.7 \%(\mathrm{~N}=14)$ had high levels. There was no significant difference between a child's caries experience and parent's knowledge $(p>0.05)$. But, parents of children with low dmft, significantly had better attitudes $(p<0.05)($ Table 4$)$.

\section{DISCUSSION}

This study evaluated parents' knowledge and attitude about the importance of PTF in preventing caries and its relationship with the mean dmft scores in children. Because of the low amount of fluoride in Ahvaz city that diminished by water purification [7], it seems that parents' knowledge of topical ways to reach fluoride to the tooth surface could be valuable. The results of this study displayed that parental knowledge and attitudes require improvement. Through enhancing parents' knowledge about caries preventive methods, their use of these methods could increase and lessen the cost and pain required for dental treatment $[18,19]$ Fluoride has been shown to have significant anti-caries properties, and caries incidence is effectively decreased by using fluoride [5] The findings of this study showed that most parents' level of knowledge $(68 \%)$ about PTF is poor, which is similar to the results of other studies in Iran in the past few years $[13,20]$. In the study of Hendaus, $70 \%$ of parents were unaware of the presence of fluoride varnish in Qatar [14]. But, some studies demonstrated a higher level of parents' knowledge about preventive methods $[15,18,20]$. Despite this, the experience of PTF in those studies was still low [18] About the relationship between parent's attitude and PTF experience, In Herrera's study, $57.1 \%$ of mothers had a positive attitude toward fluoride, but the history of PTF in children was $3.1 \%$ [21]. In the Slayton study, until age 3 , only $19 \%$ of children with a history of previous visits to the dentist had experienced PTF [16]. In fact, parents' higher knowledge levels can not assure more children 
experience of PTF. In addition to the role of parents, dentists also contribute to the history of PTF in children, so that in a study in the UK, only $14 \%$ of dentists used fluoride varnish for children with a history of interdental caries and children who had routine visits to the dentist also had a low history of getting instructions about dental caries prevention in diet, oral hygiene, and fluoride [22]. In the Akbar study [23], the most important reason why dentists did not apply PTF was about its effectiveness assurance. Also $31 \%$ dentists believe that caries is a multifactorial disease that can not be prevented by fluoride application. In the study of Bonetti, the most common reason why dentists did not use fluoride was that they did not have enough time to visit children and did not have the skills to perform PTF [24].

In our study, parents' answers to general questions about the role of fluoride in caries prevention and its antimicrobial effect were better than other questions. Parental attitudes toward fluoride role in preventing caries were also good; however, they were often wrong about toxicity and nausea. In other studies, parents were well aware of the role of fluoride as a substance that prevented decay and was weak in other aspects such as fluoride toxicity $[13,14,25]$.

However, there are proven benefits of fluoride in preventing dental caries and parents' positive knowledge and attitudes about it, and it appears to be barriers to PTF that need further investigation. One way to increase the use of preventive therapies is to be aware of the barriers that parents face in accepting and acting on them. In our study, the most negative comments were about the toxicity and effectiveness of fluoride. In Freeman's study, children's anxiety and cost were among the barriers to accessing dental services [26]. In Kelly's study, the history of parents' poor dental experience, parents' knowledge of the importance of dental health in child health, and parental responsibility were among the factors influencing parents' use of preventive methods. Also, parents with low socioeconomic status are less expected to receive preventive treatment for their children [27].

In a systematic review, dentists' adherence to providing preventive methods was multifactorial and dependent on their ongoing education and training. Another factor that hindered dentists was low pay or coverage by private health insurance for preventive treatments [28]. The findings of a study among Iranian dentists showed acceptable levels of knowledge about the effects of topical and systemic administration of fluoride and the positive attitude of dentists towards the preventive effect of fluoride, especially in children $[29,30]$ On the other hand, concerns about the toxic effects of fluoride were reported by about one-third of dentists. However, only half of the respondents properly managed the high-risk presented as patient scenarios [29]. This indicates the need for more emphasis on dentists to allocate some time for presenting instructions about caries prevention to their patients besides the treatment of dental caries. In addition, it appears that in general courses and training of dentists, it is necessary to make them aware of the importance of the dentist's role in the prevention of dental caries.

In this study, the comparison of parents' knowledge, attitude, and performance towards the use of fluoride based on demographic variables was also examined. The findings of this study showed that there is no statistically significant relationship between parents' knowledge and gender, age, educational degree, chief complaint, and source of information. In Wyne's study [15], age and gender were not associated with knowledge, and in Tahani's study, gender and economic status were not associated with knowledge [13]. In some studies, there was a relationship between knowledge and education [7,21-23,31], but in Hendaus'study similar to our results, knowledge was not related to education [14]. This can be due to parental access to various sources of information and the impact of multiple factors on parental knowledge. In our study, similar to Tahani's study, there was no relationship between the source of information and parental knowledge, and most parents' information was given instructions through social media [13]. But in Blumer's study [32], most parents were informed by the dentist's; moreover, parents that were educated by a dentist had greater knowledge and attitude, so it can be concluded that if dentists become parents' source of information, their practice in preventive methods utilization may improve.

In this study, in addition to parental knowledge and attitude, the history of PTF treatment was also examined, which, unfortunately, there were low PTF experiences. Given the importance of fluoride in the prevention of caries and the high prevalence of caries among Iranian children [2], it is necessary to increase parents' knowledge and attitude towards preventive methods and, subsequently, increase their use of these treatments. Due to the parents' lack of knowledge about the methods of preventing caries, most of them go to the dentist when preventive treatments are no 
longer possible, and the teeth need to be restored, pulp treatment, or even extraction, which causes more pain and cost for them $[31,33,34]$. Moreover, providing firstchild dental visit before age one and recommended age for PTF by the American Pediatric Dental Association (AAPD) is not engaged [35] and most children didn't have their first dental visit up to the age of three [16]. According to dentists' opinions, one of the reasons for not providing instructions to parents before the age of one was that parents did not pay attention to this subject and did not refer to them [36,37] In a systematic review, The main factors that dentists believed keep patients from performing preventive measures were "lack of understanding of the benefits" (17\%), "age.small children" (12\%), and "patient lack of motivation" (8\%) [28].

Counseling and training parents can be helpful in improving oral health programs, and perhaps resulting in more use of fluoride varnish. Motivational interviewing (MI) is also a way to increase parental knowledge and encourage them to benefit preventive methods [38] Dentists, especially pediatricians, can play an important role in this treatment by advising parents. Programs aimed to increase parental access to dental services, such as the $A B C D$ program in Washington, DC, in collaboration with dentists, insurance, physicians, and pediatricians, have been effective in reducing caries and increasing children's referrals for PTF [39]. The use of public fluoride varnish programs has been effective in reducing caries and the need for dental restorations in the future $[39,40]$. Currently, fluoride varnish application public program is being implemented in Iranian schools from the age of six, but considering that the sooner PTF started is more effective, the development of such programs with the company of other organs such as health and insurance could lead in more access to preventive cares for preschool children. Also, as long as the main source of parental information in our study was social media, it would be necessary to establish programs to inform parents.

One of the limitations of this study is that it is crosssectional because long-term studies provide more reliable information. In our study, the information was obtained according to the parents' statements that if there were ways to check the accuracy of the parents' answers, the study would be more reliable.

\section{CONCLUSION}

Parents' knowledge and attitudes toward PTF in their children were low. Due to the fact that PTF is one of the most effective methods for dental caries prevention, especially in developing countries. Establishing preventive programs for preschool children and informing parents through social media recommended.

\section{ACKNOWLEDGEMENT}

This project has been supported by the Ahvaz Jundishapur University of Medical Sciences Research Center grant \#98200. The authors would like to thank Dr. Mahdi Pourmahdi for the statistical analysis of this study.

\section{REFERENCES}

[1] Mouradian WE, Wehr E, Crall JJ. Disparities in children's oral health and access to dental care. JAMA 2000; 22; 284(20): 26252631.

https://doi.org/10.1001/jama.284.20.2625

[2] Ghasemianpour M, Bakhshandeh S, Shirvani A, Emadi N, Samadzadeh H, Fatemi NM, Ghasemian A. Dental caries experience and socioeconomic status among Iranian children: a multilevel analysis. BMC Public Health 2019; 1; 19(1): 1569. https://doi.org/10.1186/s12889-019-7693-1

[3] American Academy of Pediatric Dentistry.Perinatal and Infant Oral Health Care. Available from: https://www.aapd.org. research.oral-health-policies--recommendations.perinatal-andinfant-oral-health-care [Accessed 15 May 2020].

[4] Evans RW. The Monitor Practice Program: implications for dentistry and dental education. Aust Dent J 2019; 64(2): 193-198. https://doi.org/10.1111/adj.12676

[5] Petersen PE, Lennon MA. Effective use of fluorides for the prevention of dental caries in the 21st century: the WHO approach. Community Dent Oral Epidemiol 2004; 32(5): 319-321. https://doi.org/10.1111/j.1600-0528.2004.00175.x

[6] Azami-Aghdash S, Ghojazadeh M, Pournaghi Azar F, NaghaviBehzad M, Mahmoudi M, Jamali Z. Fluoride concentration of drinking waters and prevalence of fluorosis in Iran: a systematic review. J Dent Res Dent Clin Dent Prospects 2013; 7(1): 1-7.

[7] Jaafari-Ashkavandi Z, Kheirmand M. Effect of home-used water purifier on fluoride concentration of drinking water in southern Iran. Dent Res J (Isfahan) 2013; 10(4): 489-92.

[8] Vermaire JH, Van Exel NJ, Van Loveren C, Brouwer WB. Putting your money where your mouth is: parents' valuation of good oral health of their children. Soc Sci Med 2012; 75(12): 2200-2206. https://doi.org/10.1016/..socscimed.2012.08.018

[9] Walshaw EG, Adam NI, Palmeiro ML, Neves M, Vernazza CR. Patients' and Parents' Valuation of Fluoride Varnish in the UK and Brazil. Oral Health Prev Dent 2019; 17(3): 211-218.

[10] Ghasemi H, Murtomaa H, Torabzadeh $H$, Vehkalahti MM. Perceived barriers to the provision of preventive care among Iranian dentists. Oral Health Prev Dent 2009; 7(4): 339-346.

[11] Zimmer S, Jahn KR, Barthel CR. Recommendations for the use of fluoride in caries prevention. Oral Health Prev Dent 2003; 1(1): 45-51.

[12] Latifi-Xhemajli B, Begzati A, Veronneau J, Kutllovci T, Rexhepi A Effectiveness of fluoride varnish four times a year in preventing caries in the primary dentition: A 2 year randomized controlled trial. Community Dent Health 2019; 36(2): 190-194.

[13] Tahani B, Yadegarfar G, Ahmadi A. Knowledge, attitude, and practice of parents of 7-12-year-old children towards fissure sealant therapy and professional fluoride therapy. J Educ Health Promot 2017: 106-112. https://doi.org/10.4103/jehp.jehp $17 \quad 17$

[14] Hendaus MA, Jama HA, Siddiqui FJ, Elsiddig SA, Alhammadi $\mathrm{AH}$. Parental preference for fluoride varnish: a new concept in a rapidly developing nation. Patient Prefer Adher 2016; 10: 12271233.

https://doi.org/10.2147/PPA.S109269 
[15] Wyne $\mathrm{AH}$, Al-Hammad NS, Splieth $\mathrm{CH}$. Oral health comprehension in parents of Saudi cerebral palsy children. Saudi Dent J 2017; 29(4): 156-160. https://doi.org/10.1016/j.sdentj.2017.07.004

[16] Slayton RL, Warren JJ, Levy SM, Kanellis MJ, Islam M. Frequency of reported dental visits and professional fluoride applications in a cohort of children followed from birth to age 3 years. Pediatr Dent 2002; 24(1): 64-68.

[17] WHO Oral Health Survey: Basic methods-5th ed. World Health Organization, 2013. WHO Publication. Geneva, Switzerland.

[18] Folayan MO, Kolawole KA, Oyedele T, Chukumah NM, Onyejaka $\mathrm{N}$, Agbaje $\mathrm{H}$, Oziegbe EO, Osho OV. Association between knowledge of caries preventive practices, preventive oral health habits of parents and children and caries experience in children resident in sub-urban Nigeria. BMC Oral Health 2014; 14(1): 156165. https://doi.org/10.1186/1472-6831-14-156

[19] Moura-Leite FR, Ramos-Jorge J, Ramos-Jorge ML, de Paiva SM, Vale MP, Pordeus IA. Impact of dental pain on daily living of five-year-old Brazilian preschool children: prevalence and associated factors. Eur Arch Paediatr Dent 2011; 12(6): 293-297. https://doi.org/10.1007/BF03262826

[20] Baradaran Nakhjavani Y, Forutan S, Baradaran Nakhjavani F. Mothers' knowledge about fluoride therapy and fissure sealants. Community Dent Oral Epidemiol 2013; 2(1): 1-5.

[21] Herrera, M.D.S., Medina-Solís, C.E., Pontigo-Loyola, A.P., RosaSantillana, R.D.L., Ávila-Burgos, L., Scougall-Vilchis, et al. Socioeconomic Inequalities in Visits to the Dentist to Receive Professionally Applied Topical Fluoride in a Developing Country. Int J Environ Res Public Health 2017; 14(8): 903-912. https://doi.org/10.3390/ijerph14080903

[22] Tickle M, Milsom KM, King D, Blinkhorn AS. The influences on preventive care provided to children who frequently attend the UK General Dental Service. Br Dent J 2003; 194(6): 329-332. https://doi.org/10.1038/sj.bdj.4809947

[23] Akbar AA, Al-Sumait N, Al-Yahya H, Sabti MY, Qudeimat MA. Knowledge, attitude, and barriers to fluoride application as a preventive measure among oral health care providers. Int J Dent 2018; 2018: 1-9. https://doi.org/10.1155/2018/8908924

[24] Bonetti D, Clarkson JE. Fluoride varnish for caries prevention: efficacy and implementation. Caries Res 2016; 50(Suppl. 1): 4549.

\section{https://doi.org/10.1159/000444268}

[25] Zakirulla M, Mustafa MM, Ravi KS, Alwabel YS, Aldayel MA, Alshareef WA. Knowledge of mothers about use of fissure sealant therapy and professional fluoride therapy among children in Saudi Arabia. Trop J Pharm Res 2019; 18(10): 2189-2195.

[26] Freeman R. Barriers to accessing dental care: patient factor. $\mathrm{Br}$ Dent J 1999; 187(3): 141-144.27. Kelly SE, Binkley CJ, Neace WP, Gale BS. Barriers to care-seeking for children's oral health among low-income caregivers. Am J Public Health. 2005 Aug; 95(8): 1345-51. https://doi.org/10.2105/AJPH.2004.045286

[27] Kelly SE, Binkley CJ, Neace WP, Gale BS. Barriers to careseeking for children's oral health among low-income caregivers. Am J Public Health 2005; 95(8): 1345-1351. https://doi.org/10.2105/AJPH.2004.045286
[28] Suga US, Terada RS, Ubaldini AL, Fujimaki M, Pascotto RC, Batilana AP, Pietrobon R, Vissoci JR, Rodrigues CG. Factors that drive dentists towards or away from dental caries preventive measures: systematic review and metasummary. PloS one 2014; 9(10): 1-18.

https://doi.org/10.1371/journal.pone.0107831

[29] Ghasemi H, Murtomaa H, Torabzadeh H, Vehkalahti MM. Knowledge of and attitudes towards preventive dental care among Iranian dentists. Eur J Dent 2007; 1(04): 222-229. https://doi.org/10.1055/s-0039-1698343

[30] Pakdaman A, Yarahmadi Z, Kharazifard MJ. Self-Reported Knowledge and Attitude of Dentists towards Prescription of Fluoride. J Dent (Tehran) 2015; 12(8): 550-556.

[31] Nowak AJ, Casamassimo PS, Scott J, Moulton R. Do early dental visits reduce treatment and treatment costs for children?. Pediatr Dent 2014; 36(7): 489-493.

[32] Blumer S, Ratson T, Peretz B, Dagon N. Parents' attitude towards the use of fluorides and fissure sealants and its effect on their children's oral health.J Clin Pediatr Dent. 2018; 42(1): 6-10. https://doi.org/10.17796/1053-4628-42.1.2

[33] Lee JY, Bouwens TJ, Savage MF, Vann Jr WF. Examining the cost-effectiveness of early dental visits. Pediatr Dent 2006; 28(2): 102-105

[34] Saied-Moallemi Z, Virtanen JI, Tehranchi A, Murtomaa H Disparities in oral health of children in Tehran, Iran. Eur Arch Paediatr Dent 2006; 7(4): 262-264. https://doi.org/10.1007/BF03262563

[35] Nowak AJ, Warren JJ. Infant oral health and oral habits. Pediatr Clin North Am 2000; 47(5): 1043-1066. https://doi.org/10.1016/S0031-3955(05)70257-1

[36] Mileva S, Kondeva V. Age at and reasons for the first dental visit. Folia Medica 2010; 52(4): 56-61. https://doi.org/10.2478/v10153-010-0018-x

[37] Djokic J, Bowen A, Dooa JS, Kahatab R, Kumagai T, McKee K, Tan C, FitzGerald K, Duane B, Sagheri D. Knowledge, attitudes and behaviour towards the infant oral health visit: are dentists in Ireland aware of the recommendation for a first visit to the dentist by age 1 year? Eur Arch Paediatr Dent 2019; 20(2): 65-72. https://doi.org/10.1007/s40368-018-0386-0

[38] Weinstein P, Harrison R, Benton T. Motivating mothers to prevent caries: confirming the beneficial effect of counseling. $J$ Am Dent Assoc 2006; 137(6): 789-793. https://doi.org/10.14219/jada.archive.2006.0291

[39] Grembowski D, Milgrom PM. Increasing access to dental care for medicaid preschool children: the Access to Baby and Child Dentistry (ABCD) program. Public Health Rep 2000; 115(5): 44859. https://doi.org/10.1093/phr/115.5.448

[40] Palacio R, Shen J, Vale L, Vernazza CR. Assessing the cost-effectiveness of a fluoride varnish programme in Chile: The use of a decision analytic model in dentistry. Community Dent Oral Epidemiol 2019; 47(3): 217-224. https://doi.org/10.1111/cdoe.12447

Received on 25-07-2020

Accepted on 26-08-2020

Published on 27-11-2020

\section{DOI: https://doi.org/10.6000/2292-2598.2020.08.04.11}

(C) 2020 Taravati and Lak; Licensee Lifescience Global.

This is an open access article licensed under the terms of the Creative Commons Attribution Non-Commercial License (http://creativecommons.org/licenses/by-nc/3.0/) which permits unrestricted, non-commercial use, distribution and reproduction in any medium, provided the work is properly cited. 